\title{
Exploring bicultural identities of Asian high school students through the analytic window of a literature club
}

Sapna Vyas

\section{Literacy activities supported bicultural identity-making processes in an after- school Asian literature club.}

I didn't understand the title. What did it have to do with the movie? Why did they say masala? There is nothing about things being spicy! (club meeting, 5/17)
Tina was puzzled because she thought that the movie would, in some way, literally involve a mixture of spices and, as a result, did not understand the meaning of the title. It was clear from our conversation that she was anxious to understand the meaning behind the title, now that she was living in the United States and had the "identity goal" of becoming bicultural. She was finding the process of living between two cultures quite challenging, and, through our dialogue, I learned that she was a little confused about her identity.

Forming a sense of identity is a primary developmental task during was thoroughly confused. In our after-school literature club, we were watching Mira Nair's (1991) Mississippi Masala, a movie about a young Indian American woman named Mina who feels torn between her parents' wishes and the man she loves, an African American of whom her parents do not approve as her romantic partner. The word masala in the title of the movie literally refers to a mixture of spices. In the movie, Mina's sense of identity, in a symbolic sense, comprises a mixture of different spices. She is of Indian ancestry, but lived in Uganda for most of her childhood. In the movie, she moves from Africa (with her family) to live in Mississippi. Therefore, balancing between being Indian, Ugandan, and American is a juggling act in her day-to-day life.
Vyas teaches at the University of Michigan-Flint French Hall, Flint, MI (3502-1950, USA). E-mai svyas@umflint.edu. adolescence. Throughout their junior high and high school years, adolescents grapple with questions and concerns about how they should define themselves, how others perceive them, and who they wish to be in the future (Erikson, 1980; Markus \& Nurius, 1986). Furthermore, during this crucial developmental point in their lives, adolescents often yearn for emotional autonomy from parental figures (Chen, 1999), choosing to affiliate with various peer groups within and outside of the school setting (Eckert, 1989; Lee, 1994) and making important decisions regarding their personal life and occupational choices (Marcia, 1994). Undoubtedly, this process of identity making is quite complex in its scope. 
Past research has demonstrated that this process of identity making may be particularly challenging for bicultural adolescents such as Tina, or for those who "live at the juncture of two cultures and can lay a claim to belonging to both cultures" (LaFromboise, Coleman, \& Gerton, 1993, p. 395). These students often find themselves poised at the intersection of ethnically and socially diverse cultures (Bhatti, 1999), and their different cultural "worlds" of home and school (Garret, 1995; Phelan, Davidson, \& Yu, 1998; Vyas, 2002) can contribute to the sense of duality that is often inherent in their identity making. An individual's sense of biculturalism may also vary widely, depending on how he or she perceives the two cultures and the degree to which he or she identifies with each (Phinney \& Devich-Navarro, 1997). Because thoughts and perceptions about what it means to be bicultural are different for each person, this poses a clear challenge for researchers and educators who are interested in helping these students cope with the cultural tensions that are often inherent in their identity-making experiences. The presence of this challenge points to the importance of creating "safe spaces," both within and outside of school settings, in which students can talk about and learn to deal with possible discontinuities between their different worlds.

Prior work in the areas of literacy and identity suggests that literacy can be a powerful force in the construction, exploration, and expression(s) of identity. In particular, formats such as reading or writing workshops and book clubs offer insightful ways of gaining knowledge about students' identity experiences. The current study focuses on Asian American high school students' expressions of identity in the context of an after-school literature club. In addition to being a "safe place" where students could discuss issues related to home and school discontinuities, the club also served as an analytic window into students' bicultural identitymaking processes. In the next section, I review the relevant literature on the relationship between literacy and identity and then discuss the current study in greater depth.

\section{Review of research}

A review of relevant literature on the relationship between literacy and identity reveals that relationship as bidirectional: Identity mediates the process of becoming literate and the types of literate behaviors that one subsequently engages in, while literacy education also influences and shapes an individual's sense of identity (Ferdman, 1990). In addition, the relationship between literacy and identity has been conceptualized in a variety of ways, in the specific contexts of reading (Cherland, 1994; Van Horn, 2000), writing (Graham, 1999/2000; Horowitz, 1995), oral literacy (Bell, 1997; Ladson-Billings, 1992), media literacy (Alvermann \& Heron, 2001), and multiple forms of literacy (Athanases, 1998; Henry, 1998; Noll, 1998). The relationship is explicitly connected to issues of culture as well. In an ethnographic study that examined the implementation of a multiethnic literature curriculum in two urban 10th-grade classrooms, Athanases (1998) found that students often experienced a heightened sense of pride and identity validation when identifying culturally with people and events within literary works. It is apparent that the relationship between literature and students' cultural worlds needs to be further explored (Rosenblatt, 1995) and that detailed analysis of students' written and oral responses to their readings of multiethnic literature clearly illustrates the need to examine additional promising contexts in which literacy can foster students' thinking about issues related to literature, culture, and identity.

\section{Formats used to explore literacy and identity}

Researchers and educators have used a variety of contextual formats in order to facilitate the development of a relationship between literacy and identity. Workshops are one popular format that has been used in the past. In his work, Graham (1999/2000) discussed the necessity of providing writers with multiple ways of tapping into their senses of selfhood. Through a cross-curricular 
writing workshop for preservice teachers, he emphasized the need for students to explore their writing abilities by engaging in activities that challenge their assumptions about literacy instruction as well as tap into a number of different roles that they might envision for themselves as writers. The study demonstrated that writing activities can encourage the exploration of different possibilities in relation to one's developing sense of identity. Furthermore, Henry (1998) conducted a weekly reading and writing workshop for African Caribbean girls. Her goal was to provide students with issues that were relevant in their lives so that they could ponder and reflect upon these issues and come up with their own understandings. Henry's study articulated the necessity of providing students with a sense of agency in their daily reading and writing activities so that they can make relevant personal connections to their identities.

The relationship between literacy and identity has also been studied in the context of a literature club or book club. In her work, Cherland (1994) explored the identity practices of female students who used texts as a "fantasy vehicle" in a literature club. She proposed that young women use their reading of fiction as a means of exploring new possibilities for female agency (i.e., possibilities beyond the ones that society considers to be the norm for females). As was evident in Cherland's work, literacy can be a means through which individuals shape and reshape their senses of identity. Brock (1997) uncovered the ways that book clubs can be a significant context in which second-language learners "learn to mean" in English (i.e., acquire ways of knowing and interacting that are appropriate in the school setting). In the book club setting, students are given opportunities to experiment with language in ways that are personally meaningful to them, such as by writing and talking about issues that they choose and consider to be worthy of discussion. Book clubs such as these are effective language tools that can supplement a quality bilingual program for students of immigrant backgrounds. Thus, there is a plethora of research that addresses issues relat- ed to various forms of literacy and identity. The above-mentioned literacy forums provide students with a variety of opportunities to actively create, shape, and explore their senses of identity.

\section{Examining bicultural identity in an Asian literature club}

In the current study, I examined the relationship between literacy (i.e., reading, writing, oral discussion, and media literacy) and identity in the setting of an after-school literature club for high school students of Asian descent. The development of this club was guided by current research on reading and writing workshops, literature clubs, and book clubs; however, the nature and purposes behind the activity that I developed were different. I focused specifically on the role of literacy in supporting students' processes of bicultural identity making between their home and school worlds, given that participation in these two contexts might lead to the development of discontinuities in their daily lives. Past research has clearly demonstrated that literacy activities can provide an analytic window into students' identity-making processes, but in broadening this relationship between literacy and identity to the experiences of bicultural individuals, which had not been done in the past, I anticipated that there might be additional windows for us to consider, both as researchers and educators. I sought to determine what some of these other windows might be.

This study contributes to existing research because the after-school literature club was geared toward first- and second-generation immigrant high school students of Asian descent, a bicultural population that does not appear to have been previously studied in the context of a reading or writing workshop, literature club, or book club.

Individuals of Asian descent represent more than 29 distinct subgroups that differ in language, religion, and customs (Sue \& Sue, 1987). The common stereotypical images of Asian students being the "model minority," "whiz kids," and "problem free” (Lee, 1994; Walker-Moffat, 1995) 
have lowered research interest as to their psychological well-being, which is an important reason for studying the bicultural identity experiences of this particular population. Factors such as reasons for migration, feelings toward the dominant culture, and experiences in both their native lands and the United States could potentially cause identity experiences between the two cultures to differ tremendously. As a researcher and club facilitator, I strived to provide participants with an opportunity to voice their diverse views as culturally different individuals of Asian descent, in opposition to the larger umbrella term Asian, which potentially undermines exploration of the differences between groups from different Asian nations.

Furthermore, as was evident in a review of the literature on the relationship between literacy and identity, the majority of studies have focused on the relationship between one type of literacy activity (e.g., reading, writing, oral literacy) and identity. This study contributes to existing research because it explores themes and patterns that emerge across multiple types of literacy activities (i.e., reading, writing, oral discussion, and media literacy) and examines their function in students' bicultural identity-making experiences.

The research question that I addressed was this: What are the different ways that literacy activities serve as an analytic window into bicultural students' identity-making processes?

\section{Participants and setting}

The study involved 7 high school students who were interested in exploring Asian cultural issues and stated in preliminary interviews that they liked to read literature and express themselves in writing. Three of the girl students, Sook, Tina, and Wai-ling, were considered "core participants," as they attended club meetings consistently over a period of four and a half months.

Sook. A first-generation participant of Korean descent, Sook immigrated to the United
States with her mother and sister two and a half years prior to the start of the literature club. Her mother was pursuing a degree in counseling, and her parents wanted Sook and her sister to attend high school in the United States. Sook considered herself to be a visitor to the United States, which became evident in her description of herself as "forever Korean"; however, she still voiced a desire to be able to function effectively in the United States. Sook returned to Korea at the end of her senior year of high school.

Tina. A first-generation participant of Nepali descent, Tina immigrated to the United States with her two brothers and parents four years prior to the beginning of the literature club. Her parents had decided to settle permanently in the United States in order to provide their children with higher educational opportunities. Tina expressed that she considered herself "Asian American" because she needed to define herself this way in order to function effectively in the United States.

Wai-ling. A first-generation participant of Taiwanese descent, Wai-ling and her brother joined her parents, who were already permanently settled in the United States, four years before the start of the literature club. She considered herself to be "Asian" but acknowledged that she found aspects of American culture appealing to her sense of self.

The others, including all of the male participants, were more peripheral participants, and their attendance at club meetings was inconsistent due to other extracurricular activities, such as sports and after-school jobs. Three of them, Ramesh, Kiran, and Sudeep, were male and of Indian descent; the fourth, Nasreen, was a female of Pakistani descent.

The research site was a public high school in an upper middle class suburb in the state of Michigan. This suburb is located near a large state university, and so a vast majority of students at the school are affiliated with the university through parents or older siblings. Students of 
Asian descent make up 7\% of the total student population at this particular high school, which is 86\% European American.

\section{Description of club meetings}

The after-school club took place in the classroom of a reading teacher who had worked extensively with Sook, Tina, and Wai-ling in an ESL (English as a Second Language) classroom setting.

Club meetings lasted one hour, once a week. A typical session would begin after the school day was over. First, we would often catch up on nonclub matters, making general comments about how the week was going and revealing emotional responses to events that had taken place during the school day or to particular class assignments.

Next, I would introduce the reading(s) for the day. In preparation for each meeting and with the input of club participants, I chose literature (i.e., poems, short stories, and children's books) written by authors of Asian descent or that dealt with issues of particular relevance to the experiences of individuals of Asian descent. I tried to choose literary works that could be read within the confines of a club meeting, works that did not contain difficult words that first-generation immigrant students might not readily comprehend. In addition, the chosen literature dealt with themes that might affect these high school students' identity development between home and school in varying ways and, in turn, have the potential of being a projective device for participants' identity experiences. I would preface our conversation by providing students with some context about the particular reading for the day. If we were reading a children's picture book, then we would take turns reading a few pages each. If we were reading a longer piece of literature, students would usually come prepared to discuss the reading. During our meetings, students would share their general impressions of a given literary work and raise questions that arose in their minds while reading. As the club facilitator, I would often gear the conversation toward two or three related topics that I wanted to discuss on that particular day. Discussion topics typically related to events or characters in the stories we read, and I asked students to extend their understanding of the reading by applying similar situations to their own lives or by viewing a particular situation from a character's perspective. On days when students were very engaged in the reading, they often talked extensively about their lives, sometimes making little or no reference to the readings. On days when students were not as engaged in the reading, I often had to probe in order to get them to contribute to discussion. On such occasions, I sometimes asked students to reflect about the readings in writing. Students were encouraged to share their written reflections with the group but not required to do so. We also watched movies, such as Joy Luck Club (Wang, 1993) and Mississippi Masala (Nair, 1991) and discussed them at length with one another.

\section{Data sources and analysis}

Qualitative data from club meetings, interviews, and written reflections were analyzed using the constant comparative method (Creswell, 1994), in which key issues, themes, or patterns in the data were initial categories of focus. Data were systematically collected and coded in the form of an evolving, descriptive catalog of themes, in order to qualitatively describe the role of literacy in supporting bicultural identity development. The themes generated included literacy activities as an analytic window into bicultural students' interpretations, beliefs, personal choices, and decisions.

\section{Personal interpretations and beliefs}

Literacy activities served as a window into students' personal interpretations and beliefs within the after-school club.

Providing rationales for characters' intentions. In their reading of literature, students often tried to 
interpret characters' intentions. In "Homecoming" (Chang, 1997), Su-Lin's father is often very strict and harsh with her. When she was younger, he became enraged once when she was watching television without his permission. He did not typically allow his children to watch television unless it was a news program. As Su-Lin fumbled to come up with an excuse for why she had been watching television, her father started to yell and threatened to spank her. She retorted by saying, "We're in America, Ba-ba! You can’t spank me-if you do, I'll report you to the police for child abuse!" (p. 47). He replied that if she wanted to be considered American, he would treat her like an American: At the age of 18 , she would leave the house, and he would no longer support her financially. He took out a piece of paper and made her sign a contract that she would leave the house at 18 . When she did eventually turn 18 , he made her leave.

Sook and Tina had different interpretations of the father's reasons for treating his daughter in this particular manner. Tina, who frequently drew distinctions between "us" (i.e., individuals of Asian descent) and "them" (i.e., individuals of European American descent), believed that the father's actions and behaviors reflected an "American way" of dealing with situations:

I think her dad was mean to her because now he is in a different place, he is in America. His mind is like an American person. He knows the American way. (club meeting, 2/16)

Hence, Tina viewed the father's actions and behaviors as situational. According to her, it was unlikely that the father would have reacted the way he did had he been in Taiwan. Sook, on the other hand, saw the situation differently:

Maybe her father feels sorry towards her because he left her in Taiwan and did not succeed in America. He probably feels sorry that he cannot give anything to her. (club meeting, 2/16)

As a baby, Su-Lin was left behind in Taiwan when her parents decided to emigrate to the

\section{ADOLESCENT LITERATURE REFERENCES}

Chang, C.F. (1997). Homecoming. In E.H. Kim \& L. Villaneuva (Eds.), Making more waves: New writing by Asian American women (pp. 43-53). Boston: Beacon Press.

Kaila, S. (1998). "Stained glass window." Unpublished poem.

Nguyen, L. (1993). Rain music. In L. Yep (Ed.), American dragons: Twenty-five Asian American voices (pp. 155-160). New York: HarperCollins.

Sharma, R. (1995). What's in a name? In R. Rustomji-Kerns (Ed.), Living in America: Poetry and fiction by South Asian American writers (pp. 67-68). Boulder, CO: Westview Press.

Wang, W.C. (1990). Bacon and coffee. In S. Watanabe \& C. Bruchac (Eds.), Home to stay: Asian American women's fiction (pp. 96-105). New York: Greenfield Review Press.
United States. Sook felt that the father's reaction could be attributed to his own feelings of not being successful in America. She believed that he felt inadequate because he could not provide his daughter with things that he wished he could. Thus, students offered different interpretations for the father's intentions in this particular situation. Tina's response, in particular, was related to her stronger identification with actions and behaviors that she considered to be "less American."

\section{Revealing personal beliefs by passing judgment.} In reading stories and watching movies, students also passed judgment on characters in stories that they read, revealing their personal beliefs in the process. For instance, Sook was not pleased with the way that the father treated Su-Lin in "Homecoming": 
Her father says that she is not good at math, she is not smart, and is living in a daydream...that is not good to say to your daughter. (club meeting, 2/16)

She felt that the father should have been able to convey his point of view in a softer way.

Similarly, when we watched the movie Mississippi Masala (Nair, 1991), Tina repeatedly commented on Mina's actions and behaviors. Mina, who is of Indian descent, falls in love with an African American man. Much to her family's dismay, she dates him and eventually decides to leave home to be with him. Tina was not pleased with Mina's decision, as reflected in this conversation:

Tina: $\quad$ I didn't like the end.
Researcher:
$\begin{array}{ll}\text { Tina: } & \text { You didn't like the end? Why? } \\ & \text { that...running away from her family. } \\ \text { Sook: } & \text { I can understand that. } \\ \text { Tina: } & \text { I can understand that too. Parents are } \\ & \text { parents. First come parents, then } \\ & \text { boyfriend, or whatever. (club meeting, } \\ & \text { 5/17) }\end{array}$

Hence, Tina did not agree with Mina's decision to leave home to be with her boyfriend, because this decision did not mesh well with her own cultural values. She believed that one should always listen to one's parents, placing more importance on them than anyone else. Her belief in placing family over personal interests was revealing of a strong identification with her native Nepali culture.

Ramesh, on the other hand, described a stronger identification with mainstream American culture. In discussing Rashmi Sharma's "What's in a Name?" (Sharma, 1995), a poem that we read in the club, Ramesh wrote the following:

The second paragraph states that your name determines who you are, Indian or American. But I have not related this [idea] to my name because no matter what your name is, you are who you make yourself out to be. (written reflection, 3/8)
Although he had grown up amidst two cultures, Ramesh stressed that he did not place the same amount of significance on his Indian name as the author did. His name, in his opinion, was not completely revealing of his cultural identity. Also, unlike Tina, he felt strongly about placing his personal interests over the interests of his family. Tina's and Ramesh's differing responses are revealing of the wide range of bicultural identification that may exist within a seemingly homogeneous cultural population.

\section{Personal choices and decisions}

Within this after-school club, literacy activities also often functioned as a window into students' personal choices and decisions. This idea became apparent through the personal connections that students made to the literary works that we read. In some cases, students found themselves identifying with particular characters' roles, situations, and experiences.

Combating feelings of alienation. One afternoon, Sook appeared sullen and sad. When asked what was wrong, she mentioned that the process of reading Sanjeev Kaila's poem "Stained Glass Window" (1998) had triggered a negative memory that she had of when she first came to the United States. Less than one month after her family emigrated, Sook's parents sent her to a summer camp. In retrospect, she felt that they exercised poor judgment by sending her there, because it led to an awkward and unpleasant experience. In writing about it, Sook drew connections to Kaila's poem:

I think he was talking about stereotypes which other cultures have. In here, some people do not see people as the same as themselves.... [In camp] they were playing a game which I have played since I was little; but, one girl who was in my cabin, said, "You probably don't know how to play this game because you are not American." I was really hurt. Of course there were some differences, but we were human and my teachers [in Korea] knew how to teach the game. I think that girl really did not see me as the same as her. She probably had some kind of prejudice. (written reflection, 3/8) 
Sook's written account helped me understand the circumstances that led her to express mixed emotions about her experiences in the United States and heightened expressions of anger and sadness during conversations about immigration. Furthermore, it provided insight about why she sometimes chose to maintain distance from her Caucasian peers and, instead, spend time with other immigrant high school students who identified more strongly with their native cultural backgrounds. These actions meshed with her statements of being "forever Korean" in the United States during our conversations with one another.

\section{Decisions about dealing with parental pressure.}

During one club meeting, we discussed Longhang Nguyen's “Rain Music” (1993). This short story is about a young woman named Linh, who is torn between dating two men: a kind, academically ambitious young man named Thanh, who shares the same Vietnamese cultural background, or an intriguing, less financially stable young man named David, who does not happen to share her cultural background but, nonetheless, shares a lot of similar personal interests. She knows that her parents would be devastated if they learned of her involvement with David, because he does not "fit their mold" of a future husband for their daughter. Thanh, however, epitomizes all of the personal and cultural qualities that they would value in a mate for their daughter.

After reading this story, Wai-ling was quieter than usual. She appeared to be deep in thought. Finally, she spoke out loud:

When I was reading this story, I could kind of relate to this story. There is this guy I like who is from China, and my mom has problems with it because things are really different between China and Taiwan. He has a different family background too. Then there is this Taiwanese guy who has the same background who goes to University of Michigan, and is in the medical field. This other guy from China, he doesn't really have a nice family background. (club meeting, 5/3)
In this excerpt, Wai-ling demonstrated that she could relate to the story because she was experiencing similar life circumstances. She was also torn between two young men: one whose company she really appeared to enjoy and another whom her parents found more desirable. Although he was Asian, the young man she liked did not share her Taiwanese background. This was a problematic issue for her parents because, according to Wai-ling, they overtly disliked Chinese people and, even more important, disapproved of dating in general. Wai-ling, who found aspects of mainstream American culture (such as dating) appealing, felt conflicted because her parents did not support her "nontraditional" interests; yet, she continued to pursue the relationship with the Chinese young man behind her parents' backs. This particular instance of connecting to the literature unveiled her confusion about whether to follow her parents' wishes or her own desires. In addition, her decision to date, in some ways, illustrated her desire to become "more American."

Another instance when a student revealed a personal decision through identification with a literary character was during our reading of "Homecoming." In the story, Su-Lin receives a lot of academic and social pressure from her strict, traditional father. He is unhappy about her choice to major in English and does not appear to agree with her academic and career-related life choices. While discussing this piece with the group, Ramesh shook his head in disbelief:

Ramesh: I don't feel pressure because I have gotten past that. They [parents] don't influence me anymore.

Researcher: You mean, they don't bug you?

Ramesh: No, they just don't influence me. (club meeting, 2/16)

Ramesh drew personal connections to the text because he put himself in the shoes of the main character. His experiences with pressure, however, were markedly different than Su-Lin's. While she internalized her father's harsh and strict words 
and took them to heart, Ramesh did not place as much importance on what his parents had to say. The young woman in the story, by contrast, is torn between her father's expectations and what she desires for herself. Ramesh did not experience this type of tension because he had decided that he did not identify as strongly with his parents or home background. Discussion surrounding this story revealed that Ramesh had made the choice to identify more strongly as an American.

\section{Methods of managing intergenerational differ-} ences. One noteworthy instance was when the three students who attended a particular club meeting revealed personal choices in relation to actions taken by different characters in a short story. In "Bacon and Coffee" (Wang, 1990), a young Chinese woman is having breakfast with her mother and grandmother. Her mother is constantly criticizing things about her, such as the blonde streaks in her otherwise dark hair, the fact that she is playing her radio very loudly, and that she chooses to buy vegan bacon instead of real bacon. When the daughter bluntly announces that she is engaged to marry a European

American young man, her mother and grandmother are outraged at what they perceive to be a lack of regard for their cultural background. The young woman does not change her point of view throughout the course of the conversation, which escalates into verbal attacks and generational clashes between all participants.

The young women who attended this club meeting really enjoyed this piece and talked about the decisions they would have made in relation to characters in the story. Wai-ling, who was the least traditional in her thinking, strongly identified with the daughter's choices in the story. She said, "I think I am more like the daughter...I mean, I dyed my hair and my parents did not like it" (club meeting, 2/9). Tina, who was most traditional in her thinking, was outraged with the daughter's reaction to her grandmother, in particular. She felt that the daughter should listen to what they had to say. "If I was that girl," she said, "I would stay home and listen to my grandmoth- er" (club meeting, 2/9). She went on to talk about how she felt that the daughter's decisions conveyed her disrespect to elders and that she identified with the grandmother's point of view:

I think like the grandma...she believes in her culture, and I can see her point of view...because we are living in a different culture, and their [European Americans'] culture is different than ours" (club meeting, 2/9)

Unlike Wai-ling, Tina was quick to draw distinctions between herself and "them" (European Americans). During this conversation, Sook was physically positioned between Wai-ling and Tina and kept looking back and forth between the two as they spoke, laughing because their points of view were so different. Finally, she made this comment:

I didn't think that marrying an American boy is bad, but I think that the grandma is concerned, and I agree with her a little bit. (club meeting, 2/9)

Sook assumed more of a "middle ground" position in relation to the other two students. Unlike Tina, she did not disagree with the daughter's choice to express herself differently and, most important, her decision to marry outside of her culture; however, she did not accept her confrontational manner of interacting with her elders. She expressed the following sentiment:

\begin{tabular}{|c|c|}
\hline Sook: & $\begin{array}{l}\text { I think this is a shocking story...one day, } \\
\text { she just announces that she is engaged. I } \\
\text { would never do it like that.... }\end{array}$ \\
\hline Researcher: & You would sit down and discuss it? \\
\hline Sook: & $\begin{array}{l}\text { Yes, maybe...if she loves her grandma and } \\
\text { mother, maybe there is a better way [to } \\
\text { communicate] that would not hurt them. } \\
\text { (club meeting, 2/9) }\end{array}$ \\
\hline
\end{tabular}

This scenario was interesting, as Wai-ling and Tina consistently represented two different extremes in their thinking about the story. Sook, on the other hand, saw elements from both sides 
that were worth considering and combined these elements to form a position somewhere in the middle of the two. Hence, literacy served as a window into students' personal choices and decisions. Students not only made personal identifications with characters but also placed themselves in the roles of characters, in order to figure out how they would handle a particular situation. Their decisions about situations in the texts were revealing of their bicultural identity choices: demonstrating whether they identified more strongly with their native (or parents' native) culture, mainstream American culture, or elements of both cultures. Hence, the literature club provided these students with a safe space where they could decide to either reject or embrace the ways that the literary characters conducted their lives and, in the process, make connections to their own lives.

\section{Bridging cultural and generational gaps}

In summary, participation in literacy activities helped shed light on students' bicultural identitymaking processes. Literacy activities provided some insight on students' personal interpretations and beliefs, particularly when students placed themselves in certain characters' roles or attempted to understand characters' intentions by analyzing their actions and behaviors. Literacy activities also served as an analytic window into students' personal decisions and choices, which became evident in the meaningful connections they made between literacy activities and their experiences with family members, personal relationships, and the world at large.

This study, like other studies, points to the importance of encouraging students to make personal connections to literature that they read, both within and outside of formal school settings. Literature can serve as a springboard or starting point for students to comfortably discuss issues of relevance to their lives. In this particular study, the use of literature proved to be an effective means for learning about students' identity choices and decisions. It is likely that without the use of literature as a window, uncovering students' identity-making experiences would have been a more challenging process.

It was apparent that for some students, such as Sook, Tina, and Wai-ling, engaging in literacy activities did indeed bring some issues of identity to consciousness, as they may not have reflected on the influences of their experiences in the United States before being in the club. This heightened consciousness about identity-related issues through literacy activities, in turn, could have provided students with varied methods of analyzing situations that were new and unfamiliar to them. Because this club only met over the course of four and a half months, it only provided me with a "developmental snapshot" of the participants' identity experiences. Future research should explore the long-term implications of using a literature book club format because it appears to be a promising way to acquire rich data about the vast range of students' bicultural identity experiences.

This study moves beyond findings of past research because literacy serves as a broad, analytic window into the complex, multilayered nature of bicultural identity. Within the context of this literacy forum, characters in literature and films provided students with models of identification that they could choose to incorporate or reject in relation to their bicultural identities. There were numerous instances in which participants either demonstrated a meaningful connection to a particular character (such as Wai-ling's identification with Linh in "Rain Music") or a refusal to accept a specific character's choices and decisions (such as Tina's lack of identification with Mina in Mississippi Masala). Literacy activities also presented students with real-life scenarios in which they revealed choices and decisions that reflected the ways they viewed themselves or who they wanted to become in the future. For instance, Ramesh's reaction to Su-Lin's confrontation with her father in "Homecoming" illustrated his mindful choice to go against his parents' wishes, hence 
revealing a stronger identification with American culture. Therefore, the results of the current study support the notion that simply labeling students as "bicultural" or "Asian" does not provide an accurate depiction of their identity experiences. Choices and decisions that students reveal through literacy activities may reflect very different identity outcomes (such as considering oneself more Asian, more American, or an equal combination of both). As researchers and educators, we must delve deeper in order to recognize the vast multiplicity of perspectives that exist within a seemingly homogeneous student population. The current study is an example of how literacy activities and forums can be used to capture this depth of experience.

As Lave (1996) explicated, identity craftwork is a primary developmental project that students engage in, and the acquisition of skills and knowledge is organized by the crafting of our identities. Because how and what we learn is organized through our sense of who we are and what we are becoming, future research should focus on exploring means by which teachers may be involved in the creation and support of literacy activities that can help facilitate the process of identity making. For instance, it should focus on ways that teachers can create activities within the confines of the classroom that will lay the groundwork for the advancement of literacy and the creation of "safe spaces" for students to read, write, and discuss issues related to identity.

Future research should also focus on the development of literacy forums that help bridge possible gaps between immigrant students and their parents' experiences. In a case study of a Chinese mother reading culturally relevant texts with her Chinese American daughter over the course of 10 months, Packard (2001) discussed the importance of merging literacy and cultural activities within the context of informal family and community contexts. Therefore, literacy activities organized around the notion of such an "intergenerational exchange" could provide an effective means to address intercultural and intergenerational gaps be- tween different generations of immigrant families, with the goal of reducing bicultural identityrelated challenges and tensions.

As researchers and educators, it is important for us to offer extended support in the form of literacy forums (either within or outside of school settings) in order to better understand the identity experiences of all students seeking guidance and support amid participation in multiple worlds. This will aid us in our quest to learn more about the various factors that shape their unique identities.

\section{REFERENCES}

Alvermann, D.E., \& Heron, A.H. (2001). Literacy identity work: Playing to learn with popular media. Journal of Adolescent \& Adult Literacy, 45, 118-122.

Athanases, S.Z. (1998). Diverse learners, diverse texts: Exploring identity and difference through literary encounters. Journal of Literacy Research, 30, 273-296.

Bell, J. (1997). Literacy, culture, and identity. New York: Peter Lang.

Bhatti, G. (1999). Asian children at home and at school. London: Routledge.

Brock, C.H. (1997). Exploring the use of book club with second-language learners in mainstream classrooms. In S.I. McMahon \& T.E. Raphael (Eds.), The book club connection (pp. 141-158). New York: Teachers College Press.

Chen, Z. (1999). Ethnic similarities and differences in the association of emotional autonomy and adolescent outcomes: Comparing Euro American and Asian American adolescents. Psychological Reports, 84, 501-516.

Cherland, M.R. (1994). Private practices: Girls reading fiction and constructing identity. London: Taylor \& Francis.

Creswell, J.W. (1994). Research design: Qualitative \& quantitative approaches. London: Sage.

Eckert, P. (1989). Jocks and burnouts: Social categories and identity in the high school. New York: Teachers College Press.

Erikson, E. (1980). Identity and the life cycle. New York: W.W. Norton.

Ferdman, B.M. (1990). Literacy and cultural identity. Harvard Educational Review, 60, 181-204.

Garret, M.W. (1995). Between two worlds: Cultural discontinuity in the dropout of Native American youth. The School Counselor, 42, 186-195.

Graham, R.J. (1999/2000). The self as writer: Assumptions and identities in the writing workshop. Journal of Adolescent \& Adult Literacy, 43, 358-364.

Henry, A. (1998). "Speaking up" and "speaking out": Examining voice in a reading/writing program with 
adolescent African Caribbean girls. Journal of Literacy Research, 30, 233-252.

Horowitz, R. (1995). Orality in literacy: The uses of speech in written language by bilingual and bicultural writers. In D.L. Rubin (Ed.), Composing social identity in written language (pp. 47-74). Mahwah, NJ: Erlbaum.

Ladson-Billings, G. (1992). Liberatory consequences of literacy: A case of culturally relevant instruction for African American students. Journal of Negro Education, 61, 378-391.

LaFromboise, T., Coleman, H.L.K., \& Gerton, J. (1993). Psychological impact of biculturalism: Evidence and theory. Psychological Bulletin, 114, 395-412.

Lave, J. (1996). Teaching, as learning, in practice. Mind, Culture, and Activity, 3, 149-164.

Lee, S.J. (1994). Behind the model-minority stereotype: Voices of high and low achieving Asian American students. Anthropology \& Education Quarterly, 25, 413-429.

Marcia, J.E. (1994). The empirical study of ego identity. In H. Bosma (Ed.), Identity and development: An interdisciplinary approach (pp. 67-80). Thousand Oaks, CA: Sage.

Markus, H., \& Nurius, P. (1986). Possible selves. American Psychologist, 41, 954-969.

Nair, M. (Director). (1991). Mississippi masala [Motion picture]. United States: Columbia TriStar Home Entertainment.

Noll, E. (1998). Experiencing literacy in and out of school: Case studies of two American Indian youths. Journal of Literacy Research, 30, 205-232.
Packard, B.W. (2001). When your mother asks for another book to read: Fostering an intergenerational exchange through shared reading of culturally relevant books. Journal of Adolescent \& Adult Literacy, 44, 626-633.

Phelan, P., Davidson, A.L., \& Yu, H.C. (1998). Adolescents' worlds: Negotiating family, peers, and school. New York: Teachers College Press.

Phinney, J.S., \& Navarro-Devich, M. (1997). Variations in bicultural identification among African American and Mexican American adolescents. Journal of Research on Adolescence, 7, 3-32.

Rosenblatt, L. (1995). Literature as exploration. New York: Modern Language Association of America.

Sue, D., \& Sue, S. (1987). Cultural factors in the clinical assessment of Asian Americans. Journal of Counseling and Clinical Psychology, 55, 479-487.

Van Horn, L. (2000). Sharing literature, sharing selves: Students reveal themselves through read-alouds. Journal of Adolescent \& Adult Literacy, 43, 752-763.

Vyas, S. (2002). Am I Indian, American, or Indian American? Studying the identity experiences of Indian bicultural adolescents. In C. Park, A.L. Goodwin, \& S. Lee (Eds.), Research on the education of Asian and Pacific Americans (pp. 129-154). Greenwich, CT: Information Age.

Walker-Moffat, W. (1995). The other side of the Asian American success story. San Francisco: Jossey-Bass.

Wang, W. (Director). (1993). Joy Luck Club [Motion picture]. United States: Hollywood Pictures Home Entertainment. 